\title{
CITOHISTOLOGÍA EN FITOLOGÍA Y FITOPATOLOGÍA
}

\author{
Martin Poveda*, Leidy Díaz**, Dennice Alvarez**, Jimena Restrepo**
}

\section{Resumen}

El propósito fundamental de esta publicación es dar a conocer cómo la histología es la ciencia que estudia todos los tejidos orgánicos, su estructura, desarrollo y fisiología. En la actualidad dicha técnica está dedicada al procesamiento de los tejidos del cuerpo humano en el campo laboral de tecnólogo en citohistología. Es importante darle utilidad en el área de la botánica siendo la ciencia que estudia el tejido vegetal y su influencia en el medio ambiente. Para los tecnólogos en citohistología sería un excelente campo de acción ya que ha a diario se resalta la importancia del medio ambiente y la preocupación por conocer en detalle la fitología y sus diferentes patologías, con el fin de apoyar a los profesionales como biólogos, fitólogos, fitopatólogos e ingenieros agrónomos, así como la participación en proyectos de investigación de diferentes plantas en la evolución vegetal, cuyas características visibles al microscopio servirán como herramienta aplicable en la selección y mejoramiento de cultivos o especies vegetales en vía de extinción.

Palabras clave: técnica histológica en plantas, fitología, fitopatología, tejido vegetal.

\section{CYTOHISTOLOGY IN PHYTOLOGY AND PHYTOPATHOLOGY}

\section{Abstract}

The main objective of this publication is to disseminate knowledge on histology as the science that studies the structure, development and physiology of all organic tissues. Currently this technique is dedicated to human tissue processing as performed by cytohistology technicians. It is important that cytohistology becomes useful in botany as the science that studies vegetal tissue and its influence on the environment. It would be an excellent field of action for cytotechnologists due to the daily emphasis placed on environmental importance and current ongoing concern on a thorough understanding on phytology and its various pathologies, in order to support biologists, phytologists, phytopathologists and agricultural engineers, as well as, participating in research projects on different plants in vegetal evolution, whose microscopic features will serve as applicable selection tools to improve crops or endangered vegetal species.

Key words: histological technique in plants, phytology, phytopathology, vegetal tissue.

Fecha recibido: marzo 26 de 2012 - Fecha aceptado: abril 27 de 2012

* Instructor Asociado, Secretario Académico de la Facultad de Citohistología, Fundación Universitaria de Ciencias de la Salud, Bogotá DC. Colombia.
** Estudiantes de la Facultad de Citohistologia, Fundación Universitaria de Ciencias de la Salud, Bogotá DC. Colombia. 


\section{Introducción}

El objetivo de este artículo es el de ser útil no solo a los estudiantes y profesionales de la carrera de biología, sino también a los docentes y a todas a aquellas personas interesadas en el conocimiento de la anatomía vegetal, además invita a los tecnólogos de citohistología el ingreso al campo laboral en la técnica histológica en la botánica y expone de forma clara, sencilla e inmediata las técnicas que se siguen en el procesamiento histológico para la elaboración de preparaciones anatómicas. La observación y el registro de los tejidos vegetales con las preparaciones permanentes para estudios microscópicos son indispensables como fuente de investigación básica, tanto en la botánica formal como en la realización de cursos no formales especializados.

Todas las plantas están formadas por el mismo tejido dérmico fundamental y vascular, sin embargo, la manera como están organizadas sus células dentro de cada uno es muy variable, haciendo que las diferencias estructurales entre las plantas sean notables. Para tratar con éxito una planta es necesario saber algo sobre su historia de vida, el estado fisiológico en que se encuentra, su estructura física, su forma de crecimiento y en lo posible las propiedades químicas de los principales componentes estructurales de los tejidos y la probable reacción de sus contenidos celulares con los reactivos a los cuáles serán sometidas las muestras. ${ }^{1-4}$

Para llegar a un conocimiento profundo de la técnica histológica en plantas es importante conocer el origen de los conceptos. La historia de los hallazgos y las vías que han abierto camino a las ideas ayudan a comprender cada especialidad de la técnica. ${ }^{5}$ El conocimiento de la historia de una especialidad y sobre todo la selectividad a episodios o procesos importantes, tiene gran valor para mostrar cómo funciona el método de esta ciencia botánica. ${ }^{6-8}$

Se denomina técnica histológica al conjunto de procedimientos aplicados a un material biológico (animal o vegetal) con el fin de prepararlo y conferirle las condiciones óptimas para poder observar, examinar y analizar sus componentes morfológicos a través de los microscopios óptico y electrónico. ${ }^{9-12}$ Las preparaciones permanentes para estudios microscópicos son indispensables como fuente de investigación básica, tanto en botánica formal como en la enseñanza en cursos no formales especializados. ${ }^{13-16}$

Todas las plantas están formadas por el mismo tejido dérmico fundamental y vascular. ${ }^{17}$ Sin embargo, la manera como están organizadas sus células es muy variable, haciendo que las diferencias estructurales entre las plantas sean notables. ${ }^{18,19}$

Para tratar con éxito una planta es necesario saber algo sobre su historia de vida, el estado fisiológico en que se encuentra, su estructura física, su forma de crecimiento ${ }^{20,21}$ y en lo posible las propiedades químicas de los principales componentes estructurales de sus tejidos, así como la probable reacción de este y de sus contenidos celulares con los reactivos a los cuales serán sometidas. ${ }^{22,23}$

Las plantas son organismos multicelulares formados por millones con funciones especializadas. En la madurez las estructuras de dichas células especializadas pueden diferir mucho entre sí, aunque todas las de origen vegetal tienen la misma organización eucariota básica. ${ }^{24-26}$ El termino célula deriva del latín cella que significa celda, término empleado por primera vez en biología en 1665 por el botánico ingles Robert Hooke para describir las unidades individuales de la estructura del tejido. Una diferencia fundamental entre las plantas y los animales es que cada célula vegetal está rodeada por una pared celular rígida y unidas a través de la lámina media. ${ }^{27,28}$ En consecuencia el desarrollo vegetal, a diferencia del animal, depende solo de los patrones de división y crecimiento celular. La mayoría de las plantas vasculares que existen en la actualidad sobre la tierra presentan un plan estructural denominado cormo, en el cual la división de trabajo requerida para la vida en el medio terrestre y aéreo ha dado lugar a tres órganos básicos: raíz, tallo y hoja. ${ }^{29-31}$ Unos de los procedimientos técnicos que apoya a la biología, la botánica y las ciencias afines, reposa en estudiar o examinar los tejidos vegetales tanto de manera fisiológica como patológica mediante la preparación histológica. ${ }^{32,33} \mathrm{El}$ primer órgano que aparece en las 
plantas vasculares más primitivas es el tallo. A partir de él, por diversos procesos surgen las hojas y la raíz ${ }^{34-36}$, y cada uno de estos órganos cumple funciones particulares, las cuales a su vez determinan su forma externa y su estructura interna. En la actualidad para algunos estudios que requieren urgencia o en prácticas de campo se recurre a los "cortes de mano alzada" que tienen un espesor aproximado de $20 \mu \mathrm{m}^{37}$, lo que nos permite apreciar detalles estructurales sin mayor esfuerzo usando colorantes in vivo; pero para estudios más puntuales y finos no son recomendados debido al espesor, en tal caso es necesario recurrir al micrótomo para obtenerlos más delgados y seriados ${ }^{38}$ (Figura 1).

Hace mucho tiempo los botánicos reconocieron que los tejidos principales de la planta están organizados en grandes unidades que se encuentran en todas las partes del vegetal denominados sistema de tejidos y su presencia en la raíz, en el tallo y en la hoja revela tanto una similitud básica de los órganos de las plantas como la continuidad del cuerpo vegetal. Los tres sistemas de tejido son: 1) fundamental, 2) vascular y 3) epidérmico..$^{39-41}$

El objetivo de este artículo es revisar la literatura de la técnica histológica en plantas, con el fin de conocer los diferentes campos acción en el que el tecnólogo en citohistología podría desempeñarse. Como metodología se realizó una búsqueda de la literatura, en donde las

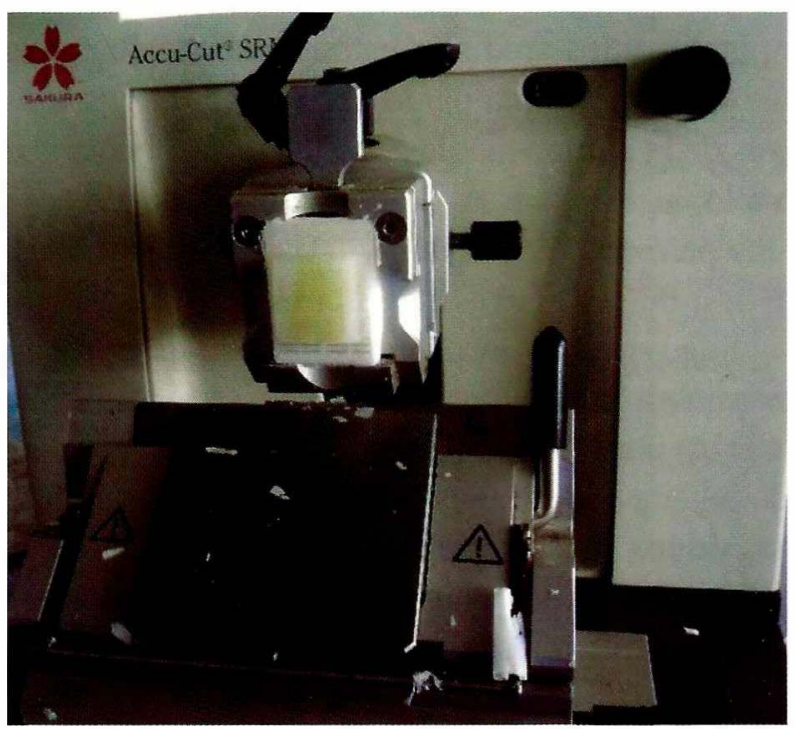

Figura I. Material vegetal en el corte. fuentes primarias fueron libros de botánica, artículos de fitología y fitopatología obtenidos de una búsqueda en la base de datos Scielo teniendo en cuenta las palabras claves histotecnología, anatomía y morfología de los órganos vegetativos.

\section{Procedimientos inmediatos o vitales}

Según lo explicado antes, cada día es mayor el número de personas interesadas en conocer y manejar las diferentes técnicas que se utilizan en el estudio de la anatomía vegetal. ${ }^{42-44}$ Se basan en la observación y el estudio de microorganismos, las células sanguíneas, las descamadas o disociadas, aquellas en cultivos de tejidos así como las estructuras delgadas y translúcidas como la membrana peritoneal de animales pequeños o epidermis de vegetales o granos de polen ${ }^{45}$, suspendidas en los líquidos de su hábitat natural o solución salina balanceada. Para una observación óptima suelen utilizarse tipos especiales de microscopios fotónicos como el de campo oscuro o el de contraste de fases, analizando así los órganos que constituyen un nivel de organización bien establecida, fundamental y funcional de los mismos ${ }^{46}$ (Figura 2).

El metabolismo fotosintético que presentan distintas plantas vasculares del Parque Natural del Cabo de Gata-Níjar (Almería) se estudió mediante histología y ultraestructura de su anatomía foliar. Se analiza-

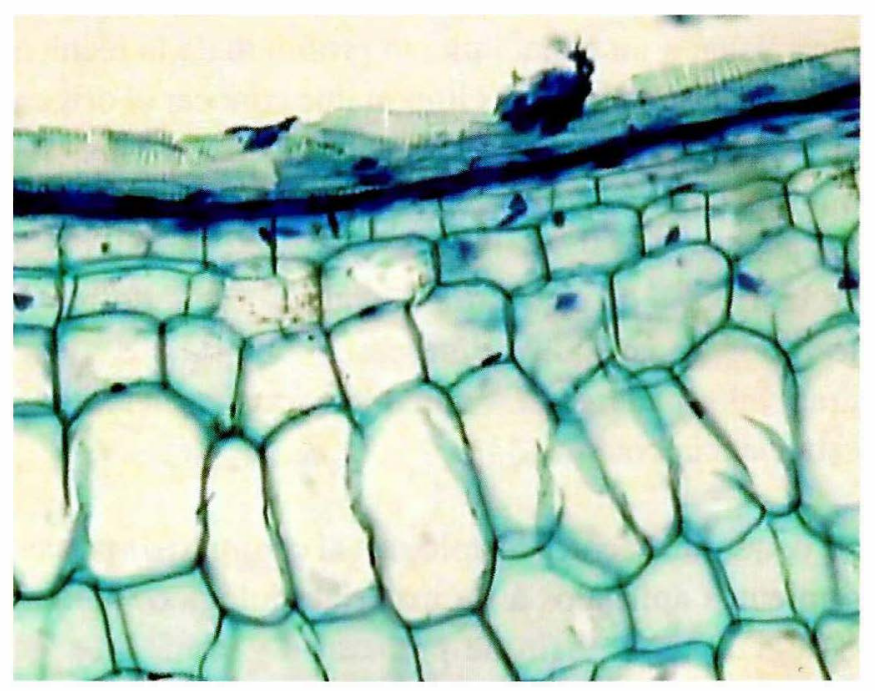

Figura 2. Células parenquimatosas y periféricas $4 X$, coloración de carmín verde metilo. 
ron veintiséis especies pertenecientes a diez familias distintas, de ellas doce resultaron ser C4, 2 CAM y el resto $\mathrm{C} 3$ siendo lo anterior una clasificación taxonómica. ${ }^{47,48}$ Además de las especies que se ajustaban a los modelos anatómicos descritos para cada tipo de metabolismo fotosintético, se encontraron variaciones sobre todo en la anatomía Kranz típica de las plantas C4. La mayoría de las especies encontradas pertenecía a la familia Chenopodiaceae y entre ellas se pudieron diferenciar tanto plantas C3 como C4. Las especies de esta familia también se distinguieron por la gran variabilidad anatómica de sus hojas, muestra de su capacidad para adaptarse a diferentes ambientes incluidos los áridos. ${ }^{49-51}$

\section{Conclusiones}

Proponer una formación académica de la técnica histológica en plantas al programa de citohistología ofreciendo material humano, tecnológico y analítico competitivo con sentido de pertenencia frente al cuidado del medio ambiente. Forjar la investigación y las aplicaciones en la salud ambiental, bienestar agronómico, nuevas fortalezas en la adaptabilidad de las diferentes plantas y novedosas sustancias con utilidad terapéutica. Plantear un campo de acción amplio para el tecnólogo en citohistología en la botánica siendo participe en el impacto ambiental de nuestro país.

\section{Referencias}

1. Montalvo Arenas CE. Técnica histológica [monografía en Internet]. México: FACMED: 2010. [citado 22 Jun 2012] . Disponible en: http://www.facmed. unam.mx/deptos/biocetis/Doc/Repaso_I/Apuntes\%20bloque\%20I/3_tecnica_ histologica.pdf

2. Kourie J, Goldsmith MH. K channels are responsible for an inwardly rectifying current in the plasma membrane of mesophyll protoplasts of Avenasatiua. PlantPhysiol. 1992 Mar: 98(3):1087-97.

3. Zeiger E, Taiz L. Fisiología vegetal. $3^{\text {a }}$ ed. Castello de la Plana, España: Universitat Jaume; 2006.

4. MontuengaBadia L, Esteban Ruiz F. Clavo González A. Técnicas en histología y biología celular. Barcelona, España: Elsevier :Masson, c2009.

5. Becerra N. Marquinez X, Barrera TE. Anatomía y morfología de los órganos vegetativos de las plantas vasculares. $1^{\text {a }}$ ed. Bogotá: Universidad Nacional. Facultad de Ciencias; 2002.

6. Programa de la signatura organografía microscópica. [monografía en Internet]. España: Universidad de Extremadura. Facultad de Ciencias; 2010. [citado 22 Jun 2012]. Disponible enhttp://ciencias.unex.es/titulaciones/biologia/programas_asignaturas_curso_proximo/2_organografia_microscopica.pdf
7. Raven PH, Evert RF, Eichhorn SE. Biología de las plantas. Barcelona, España: Reverte; 1992.

8. De Barros CS, Driemeier D, Pilati C, Barros SS, Castilhos LML. Seneciospp. poisoning in cattle in outhern Brazil. Vet. Hum. Toxicol. 1992; 34(3):241-46.

9. Sandoval E. Técnicas aplicadas al estudio de la anatomía vegetal. $1^{2}$ ed. México: UNAM. Instituto de Biología; 2005.

10. RomaniucNeto S, Wanderley MGL. Flora fanerogâmica da reserva do Parque Estadual das Fontes do Ipiranga (São Paulo, Brasil): 19 - Moraceae. Hoehnea. 1992; 19:165-69

11. González Rebollar JL, Chueca Sancho A. C4 y CAM: Características generales y uso en programas de desarrollo de tierras áridas y semiáridas. Madrid : Consejo Superior de Investigaciones Científicas : Fundación Ramón Areces, 2010

12. Paviani T. 1978. Anatomía vegetal do cerrado. Ciên Cult. 1978; 30:1076-86.

13. O`Brien TP, Feder N, McCully ME. Polychromatic staning of plant cell walls by toluidine blue O. Protoplasma. 1964; 59: 367-73.

14. Condon AG, Richards RA, Rebetzcle GJ, Farquhar GD. Improving intrinsic water - use efficiency and crop yield. Crop Sci. 2002; 42: 122-31.

15. Farquhar GD, Ehleringer JR, Hubick KT. Carbon isotope discrimination and photosynthesis. Annu. Rev. Plant Physiol. Plant Mol. Biol. 1989; 40:503-37.

16. Gerrits PO, Horobin R. The application of glycol metacrylate in histotechnology; some fundamental principles. Netherlands: State University of Groningen. Department of Anatomy and Embryology;1991

17. Hibberd JM, Quick WP. Characteristics of C4 photosyntesis in stems and petio les of C3 flowering plants. Nature. 2002; 415:451-54.

18. Johansen DA. Plant microtechique. New York: McGraw-Hill; 1940.

19. Lawlor DW. Photosyntesis: molecular, physiological and environmental proces ses. 3rded. New York: Springer Verlag; 2001

20. Stenberg L, DeNiroMJ,Ting IP. Carbon, hydrogen and oxygen isotope ratios of cellulose from plants having intermediary photosynthetic modes. Plant Physiol. 1984; 74:104-7.

21. Souza LA, Rosa SM. Morfo-anatomia do fruto emdesenvolvimento de Soroceabonplandii(Baill.) Burger, Lanjow and Boer (Moraceae). Acta sci., Biol. Sci. $2005 ; 27: 423-28$

22. Maniatis T, Fristch EF, Sambrook J. Molecular cloning: a laboratory manual New York: Cold Spring Harbour laboratory; 1989.

23. White TJ, Bruns TD, Lee S, Taylor JW. Amplification and direct sequencing of fungal ribosomal RNA genes for phylogenetics. In: Innis MA, Genfald DH Sninsky JJ, White TJ, editors. PCR Protocols: a guide to methods and applications. San Diego, CA: Academic Press; 1990.

24. Zervakis GI, Moncalvo JM, Vilgalys R. Molecular phylogeny, biogeography and speciation of the mushroom species Pleurotuscystidiosus and allied taxa. Microbiol. 2004;150: 715-26.

25. Berlyn GP, Miksche JP. Botanical microtechnique and citochemistry. Ames: The Iowa State University Press; 1976.

26. Stevens A. The haematoxylins. In: Bancroft JD, Steves A, editors. Theory and practice of histological techniques. 3rd ed. London: Churchill Livingstone; 1990.

27. Carson FL. Histotechnology: a self instructional text. Chicago, IL : American Society of Clinical; 1997.

28. Kiernan JA. Histological \&Histochemical Methods.4th ed. Bloxham, UK, Scion Publishing; 2008

29. Rawlins TE, Takahashi WN. 1952. Technics of plant histochemistry and virology. Millbrae: The National Press; 1952.

30. Sass JE. Botanical microtechnique. Ames: Iowa State Collage Press; 1951.

31. Souza LA, Rosa SM, Moscheta IS, Mourao KSM, Rodella RA, Rocha DC, Lolis MIGA. Morfología e anatomía vegetal - técnicas e prácticas. Uvaranas. Brasil: Universidade Estadual de Ponta Grossa; 2005.

32. Titford M. A short history of histopathology technique. J Histotechnol. 2006; 29:99-110 
33. Bracegirdle B. A History of microtechnique. 2nd ed. Lincolnwood, IL: Science Heritage; 1986

34. Clark G, Kasten FH. History of Staining. 3rd ed. Baltimore: Williams and Wilkins; 1983.

35. Dapson RW. The history, chemistry and modes of action of carmine and related dyes. Biotech Histochemical. 2007; 82:173-187.

36. Culling CFA. Handbook of histopathologicaltechiques. 2nd ed. London: Butterworths; 1963.

37. Sheehan DC, Hrapchak BB. Theory and practice of histotechnology. 2nd ed. St. Louis, MO: Mosby; 1980.

38. Titford M. The long history of hematoxilina. Biotech Histochem. 2005; 80:7378.

39. Wittekind DH. Romanowsky-Giemsa stains. In: Horobin RW, Kiernan JA, editors. Conn's biological stains. 10thed. Oxford: Bios Scientific Publishers; 2002. p 308.

40. Drury RAB. Wallington EA. Carlenton's histological technique. 4thed. New York, Oxford University Press; 1967.

41. Mauseth JD. Plant anatomy. Menlo Park, California: The Benjamin/Cummings Publishing Company; 1988.

42. Bayliss High OB. Lipids. In: Bancroft JD, Steves A, editors. Theory and practice of histological techniques.4th ed. New York: Churchill Livingstone; 1990.
43. Henwood A. Current applications of orcein in histochemistry. a brief review with some new observations concerning influence of dye batch variation and aging of dye solutions on staining. Biotech Histochem. 2003; 78:303-308.

44. Evert RF. Esau's Plant anatomy (meristems, cells, and tissues of the plant body: their structure, function, and development). Hoboken: John Wiley \& Sons; 2006.

45. Gatenby JB, Beams HW. The microtomist's vade-mecum (Bolles Lee). 1 th ed. Philadelphia: The Blakeston Company; 1950.

46. Pearse AGE. Histochemistry-theoretical and applied. 3rd ed. London: Churchill Livingstone; 1968.

47. Anderson G, Bancroft JD. Tissue processing and microtomy including frozen. In: Bancroft JD, Gamble M, editors. Theory and practice of histological techniques, 5th ed. Edinburgh: Churchill Livingstone; 2002. pp. 85 - 107.

48. Bancroft JD, Cook HC. Manual of histological techniques and their diagnostic application. Edinburgh: Churchill Livingstone: 1994.

49. Carson FL. Histotechnology, a self-instructional text, 2nd ed. Chicago: ASCP Press; 1997.

50. Maihisot MA. Microtomy. It`s all about technique! (workshop handout). Bowie, MD: National Society for Histotechnology; 2005.

51. Rodrigues A, Menezes M. Detecção de fungos endofíticosemsementes de caupi provenientes de Serra Talhada e de Caruaru, Estado de Pernambuco. Fitopatol. Bras. 2002; 27(5): 532-37. 